\title{
Modern Chinese Course Teaching Practice under Guidance of \\ Constructivism Learning Theory
}

\author{
Weilin Zou \\ Department of Chinese, Film and TV Communication, Changsha University, \\ Changsha, 410003, China
}

\begin{abstract}
The modern Chinese is an important course to improve language quality of students majoring in broadcasting and hosting, and radio and television editing, etc.; however, it is unable to realize the teaching goal under traditional teaching mode. The constructivism learning theory provides a beneficial reference for teaching reform of modern Chinese; it fundamentally changes teaching concept and provides effective teaching mode, and emphasizes students' subjectivity in learning activity; the teachers become the organizers and guiders in learning activity; according to students' existing knowledge experience, the teachers create teaching context close to reality, and adopt the project teaching method which emphasizes on coordination to guide students to realize the meaning construction of knowledge they have learnt.
\end{abstract}

Key words: constructivism learning theory; modern Chinese; teaching context; project teaching method

\section{Difficulties in modern Chinese course teaching for students majoring in}

\section{broadcasting and hosting, and radio and television editing}

The language quality is an essential part of college students' comprehensive quality, and it is especially important for students who will engage in radio and television related work, and "the broadcasting and hosting language plays a leading-edge, key, and bridge role in radio and television communication." ${ }^{[1]}$ Therefore, a consensus has been reached as for establishing modern Chinese course for students majoring in broadcasting and hosting, and radio and television editing, but the positioning of course property is not clear at the beginning, which can be found from curriculum provision; partial colleges regard modern Chinese as professional optional course and establish it in semester 6 with few class hours, thus both teachers and students pay little attention to this course; under this condition, after one-semester Chinese learning, the teaching content of modern Chinese is fragmented, the basic knowledge is roughly explained, and both teachers and students finish this course disappointedly. However, with continuous deepening of professional construction, the educators get a clearer and clearer knowledge of importance of language quality and literature quality on those majors, and then change modern Chinese course from professional optional course to professional basic course or subject basic course in curriculum provision, and the class hour is expanded accordingly, thus the fundamental position of modern Chinese course is confirmed. However, from perspective of teaching practice, the 
teaching mode is traditional and it focus on theoretical teaching, thus the teaching is excessively abstract and lacks of analysis on vivid language phenomenon; the teachers' teaching concept and the students' learning attitude are not thoroughly changed, and the improvement of students' comprehensive language analysis and understanding ability and verbal and literal expression ability can't benefit from the learning of modern Chinese course, thus it is hard to realize the teaching goal.

\section{Theoretical connotation of constructivism learning theory}

Compared to traditional behaviorism, the constructivism learning theory developed on the basis of cognitivism emphasizes individual's interaction in learning and teaching activity under specific context; this "individual" not only refers to learners, but also refers to educators. ${ }^{[2]}$ Therefore, the constructivism learning theory covers cognitive view, learning view, and teaching view; it thinks that the knowledge is the explanation or hypothesis on objective world and it has situationality, and the learning is a process in which the cognitive subject constructs the meaning based on his experience under specific context. The knowledge is actively constructed by learners rather than passively accepted by learners; in the conflict and collision between new and old knowledge experience, the knowledge structure is reconstructed. There are four factors which influence this bidirectional process: context, cooperation, conversation, and meaning construction. The context is the environmental basis of meaning construction, the cooperation and conversation are important means of meaning construction, and the meaning construction is the final goal of learning. The quantity of knowledge obtained depends on learners' ability to construct knowledge meaning according to their experience rather than depend on the ability to memorize the information taught from teachers. Therefore, in teaching process, it is required to pay more attention to the comprehensive function of intelligent factors (such as students' existing knowledge experience, cultural background, emotional factor, and learning motivation) and non-intelligent factors in learning activity, emphasize students' subjective function, and motivate students' initiative and creativity, and the teachers' role positioning shall be changed from dominators to guiders in learning activity, and help students to set a learning context which is suitable for meaning construction of new knowledge, organize students to cooperate with each other, carry out discussion, and complete classification and analysis on learning materials, and propose and demonstrate problems, and then guide students to realize the meaning construction of knowledge they have learnt. ${ }^{[3]}$

\section{Modern Chinese course teaching practice based on constructivism learning theory}

\section{(I) To create teaching context close to reality}

Von Glasersfeld thinks: "The only way for an organic entity to obtain knowledge is to carry out construction." ${ }^{[4]}$ However, the construction is realized through interaction between new and old experience. In order to promote and guide students to complete the construction of their knowledge, the first thing is to clearly know students' existing knowledge experience. The modern Chinese is a linguistics course which takes mother tongue as research objective; after 12-year learning of Chinese course in 
primary school and middle school, the students have had certain language knowledge and ability, that is to say, they have had the perceptual knowledge of standard pronunciation, standard vocabulary, and correct grammar of mandarin and they can use relatively standard mandarin to carry out verbal communication. However, as for modern Chinese course teaching, this knowledge experience has two sides. On one hand, it can provide students with a kind of resource and help students to actively carry out knowledge construction while the teachers provide suitable context, task, and conditions; on the other hand, it can make students have queries, for the old experience is enough for students to confront daily verbal communication, and the new knowledge is easily understood and has no new meaning, which causes their loss of motivation in knowledge construction. In previous teaching practice, the construction of new and old knowledge experience often steps into wrong region; in order to avoid the repetition with Chinese knowledge of middle school, the teachers only pay attention to systematic teaching of abstract theory and weaken the social real context close to verbal reality; the language teaching doesn't focus on social practical application, thus the students lose learning motivation.

The constructivism thinks that the teaching shall make the learning happen in the context similar to realistic context and focus on solving the problems the students meet in realistic life. ${ }^{[5]}$ The language is closely related to social life, thus the modern Chinese course teaching shall analyze language application from perspective of language and information, language and communication, and language and culture, emphasize dynamic construction of knowledge rather than static rule and representation, and place language application into various kinds of context to help students to complete knowledge construction in process of interaction with context.

\section{(II) To adopt project teaching method which emphasizes cooperation}

It is a consensus among educators that the students play a dominate role in teaching activity; however, how to exert their subjectivity is a topic which has lasted for a long time. The project teaching method is a cooperative learning mode under the guidance of constructivism theory; in the teaching context close to reality, this method takes project task as means to promote students' mutual cooperation, discussion, and communication so as to complete meaning construction of knowledge in the process of continuously solving problems.

As for application of project teaching method, firstly, the educators shall change teaching concepts, and transform the role from knowledge transmitters to guiders of knowledge construction. Instead of being taught to students as the content determined in advance, the knowledge shall be obtained via creating suitable context, and guiding students to independently find problems and explore the strategy used to solve problems. Secondly, the project design shall focus on problems to motivate students' learning motivation, and the problems must be arranged under different context so as to represent requirements of teaching goal and help students to carry out exploratory activities and have enough space to independently solve problems. The context-based problem setting not only pays attention to influence of social environment, but also pays attention to students' existing cognitive experience and emotional experience so as to ensure that the scheme is practical and of value significance. Besides, the project 
teaching method requires that the students shall change their learning way of independently obtaining knowledge, emphasizes cooperative learning, pays attention to completing knowledge construction via communication and discussion. The cooperative learning mode can be many types of team cooperation. The members of one team or different teams can carry out collection of background information in a comprehensive way through division of labor to analyze and discuss different aspects of problems and then classify the different opinions on same topic so as to realize the deeper layer of understanding and construction on meaning. This mode can break through the limitation existing in single learner's knowledge acquisition, and help promote personal ability's development through communication.

\section{Motivating project task setting}

The reform of modern Chinese course teaching method always attracts wide attention, and people mainly proposes three aspects of suggestions: the first one is that the teaching method shall be reformed in a development and democracy oriented direction; the second one is combination of learning, practice, and research; the third one is modernization of teaching means. The requirement is proposed that "there shall be firm and sufficient practice, the attention shall be paid to benefit, and the practice ways can be diversified"; meanwhile "it is required to guide students to carry out research and encourage students to suitably carry out scientific research activities in the learning process as much as possible". ${ }^{[6]}$ The project teaching method is just a kind of beneficial trial that the teaching method is done in a development and democracy oriented direction; setting motivating problems is the key to promote the combination of learning, practice, and research.

The current complicated and diversified language life is a huge context-based language resource library; in particular, the network language has become an important existence which can't be ignored. Except for a kind of verbal phenomenon, the network language is also a kind of social and cultural phenomenon, and its production, transmission, and development are closely related with social life; besides, the network language also has its development rules. However, the common teaching materials of modern Chinese at present only involve little content of network language. As the main group which uses network language, the young students have congenital interest in language tool they use everyday; therefore, in vocabulary teaching, we can take network language as object, arrange investigation task and deliver project task list before class to require students to collect and classify the network vocabulary they commonly use, and note the pronunciation, writing form and structure, analyze the meaning of the sentences they commonly use, and try to find out the origin and popular reason of those words. The completion of this task also involves many aspects of lexicology vocabulary, and it is also closely related to cultural linguistics; while the students complete the task according to existing knowledge experience, it is inevitable that they will meet some difficulties which they can't solve and then the students will propose the problems which they want to know. In the classroom teaching, we can take students' investigation and analysis as main body and take the task of solving students' problems as main line to introduce basic theory and knowledge points related to vocabulary composition, word composition, 
property of meaning of words, idiom, and vocabulary standardization, provide multiple analysis perspectives of linguistics and cultural linguistics, highlight the point, analyze the difficult points, expand the view, deepen students' problems, propose the solutions to problems in discussion, and guide means of task completion. While students find that they can give a theoretical analysis on hot network language, they will become more enthusiastic about course learning, and actively construct the knowledge they have learnt, thus their learning effect can be greatly improved.

\section{Cooperative completion of project task}

Each student has different hobby, and they have respective advantages and disadvantages; influenced by subjective factor, the personal prejudice can easily happen in the individual's independent learning; the cooperative discussion with other learners can motivate students to weaken personal prejudice from different perspectives. As the organizers of students' knowledge construction, the teachers shall pay attention to creating the environment of cooperative learning, and establishing learning community so as to effectively help students to exert their initiative in group, freely express their opinions in exploration process, show attitude on the basis of joint understanding, and provide reference suggestions. The students can apply knowledge experience in personal practice activity and show their uniqueness. ${ }^{[1]}$ The setting of motivating problems makes students complete the collection and classification of background materials, and then the students can have the ability to carry out knowledge learning cooperation based on relevant problems; due to different experience background, they pay attention to different aspects; through discussion and communication, the collision and blending will happen in their respective opinions; then, the teachers shall give a suitable intervention to provide guidance so as to make students have more acute thinking and more comprehensive knowledge construction.

Except for cooperative knowledge learning in classroom, the teachers shall organize the cooperative learning of exploratory team which aims at solving realistic problems. After specific chapter learning, the teachers shall arrange corresponding project task and organize acceptance. For example, the "rhythm of voice" tells the basic principle of stress, pause, speed, and tone in rhythm of voice, thus we can require students to establish learning teams to carry out poetry reading, dramatic performance or film dubbing, and record it as film insert to play it in 10 minutes before class, and the students of other teams give some remarks. This task both reflects course teaching requirements, and has close relationship with knowledge background of students majoring in broadcasting and hosting, and radio and television editing. While the students complete the task, the personal self-knowledge system is further enhanced through confirmation in true context; meanwhile, in communication and cooperation with students and teachers, the original knowledge structure is continuously broken, and it is also able to supervise themselves to carry out self-correction and perfect the knowledge structure.

\section{Conclusion}

Since the constructivism learning theory is introduced in China, there are many works explaining this theory and also many queries on this theory; however, there is no 
doubt that this theory has enlightenments on the teaching reform of modern Chinese course. It breaks traditional teaching mode, provides new teaching concept and teaching way, and advocates that the setting of all links in teaching activity shall focus on students' learning; the learners can independently complete knowledge construction under the teachers' organization and guidance only when the learners' subjective position is fully respected and the learning becomes learners' inner demand, and then the teaching goal of modern Chinese course can be realized.

\section{Acknowledgments}

This paper is the key project of teaching reform research of Changsha University: "Series Curriculum Provision and Teaching Practice Based on Modern Chinese” (serial No.: Z010).

\section{References:}

[1] Yao Xihuan: it is well worth doing the research on radio and television language thoughts on reading Mr. Xu Jialu's foreword made for the book Media and Language [c], edited by Yao Xihuan and Guo Longsheng, Discussion on Media Language [M], Beijing: Economic Science Press, 2004, 19.

[2] Luo Shengquan, Lu Fangfang: Teaching Transformation of Constructivism Learning Theory [J], Education Research Monthly, 2013 (4).

[3] Chen Wei: Theoretical Overview on Constructivism Learning Theory [J], Academic Exchange, 2007 (3).

[4] Zhang Guichun: Interpretation on Constructivism Learning Thoughts [J], Education Science, 2005, 21 (4).

[5] Wang Xuhong: Context Cognition Theory and Its Application in Teaching [J], Forum on Contemporary Education: subject education research, 2008 (10): 9-11.

[6] Jiang Jicheng, Liu Xiaonan: Survey Report on Chinese Philology Course Teaching Content and Teaching Materials Reform Research [J], Journal of Educational Science of Hunan Normal University, 2006, 5 (4). 